vaccination in Britain. Finally, the incident is a further reminder of the necessity of adequate surveillance of all vaccination procedures, including that against measles. As was previously said in these columns ${ }^{2}$ before the measles vaccination campaign was launched in Great Britain, it is essential that a close watch should be kept on the effects of vaccination. Only in this way can a true assessment of the vaccine in general use be obtained, and it is important that the Departments of Health should ensure that a well-planned and long-term surveillance programme is carried out.

\section{Clinical Haematology}

Haematology is not only a laboratory but also a clinical discipline. It is concerned with patients who have disorders which primarily affect the haemopoietic system just as patients may have disease of the gastrointestinal tract, of the nervous system, or of the heart. It is accepted that patients in the last three categories are best cared for by the gastroenterologist, the neurologist; and the cardiologist. In Europe and in America the patient with a blood disorder is cared for by the haematologist. But in Great Britain the development and evolution of haematology services has resulted in a haematologist whose orientation has been primarily to the laboratory. The major factor responsible for this has been the tendency for the laboratory services to be lumped together as clinical pathology. The provision of a haematology service was often the responsibility of the bacteriologist or the morbid anatomist, a responsibility often exercised through a junior colleague. It is only since the evolution of clinical pathology into four separate and distinct disciplines that departments of haematology have emerged and the haematologist has been accepted as a consultant in his own right.

This development has gone hand in hand with an increasing involvement of the haematologist in the direct care of patients. Though he has direct control of beds in only a few hospitals, in many more he has outpatient facilities both for seeing new patients and for following up the old ones. Today the majority of patients with bleeding disorders are cared for by the haematologist. The investigation of patients with megaloblastic anaemias or haemolytic anaemias generally falls entirely within his sphere, though often in practice the physician's name above the bed is not that of the haematologist. Similarly in some centres the management of leukaemia falls primarily to the haematologist. Thus the tendency is for the haematologist to recognize that he must also be a physician and to take an increasing share in the management of patients with blood disease. It is because haematology is both a laboratory as well as a clinical discipline that it has proved so attractive to many young doctors entering the laboratory today.

It is against this background that the report of the Committee on Clinical Haematology set up by the Royal College of Physicians should be assessed. ${ }^{1}$ The report states that " it is undeniable that much of the clinical care of patients with diseases of the blood, falls under the head of General Medicine" ; that "it is inappropriate for patients suffering from such complaints to be under the clinical care of one whose work is essentially in the laboratory"; "it contravenes the universally accepted principle that ultimate responsibility for the bedside care of the patient must rest upon one man. In this instance he should clearly be a physician, and a physician who should be sufficiently well trained and well informed to collate all the evidence, to take the final decision, and to see that it is implemented."

Does the report imply that the haematologist being trained in Great Britain today is unfit to take this responsibilitythough he continues to carry out " the bulk of haematological examinations"? To some readers it may seem to do so. The report proposes the creation of the new grade of clinical haematologist. Such a clinical haematologist, the report says, should be on the staff of every large general hospital. The first three years of his training will include one year in a haematology laboratory, and a further three or four years will be used to obtain further specialist experience of general medicine and clinical and laboratory haematology. This training would apparently be obtained in hospitals where "clinical haematology" as distinct from "laboratory haematology" is practised. Would he be expected to be a member of the Royal College of Physicians rather than the College of Pathologists ?

The result of the report's proposals would seem to be the creation of two kinds of haematologists-a clinical haematologist to take overall care of patients with blood disorders and a laboratory haematologist to provide a routine haematology service. A working party set up by the College of Pathologists is studying the report, so that the statement in it that the document has "the full approval and support" of the College of Pathologists may well be premature.

If this report is put into effect, some haematologists fear that it may have a harmful effect on recruiting to "laboratory" haematology once clinical contact with patients is removed to departments of clinical haematology. The ablest recruits will prefer to practise clinical haematology, and the service departments of haematology may find themselves starved of medically trained staff. The creation of two kinds of haematologist could in fact sow the seeds of discord.

The merit of the Royal College's report is that it has drawn attention to the unsatisfactory state in which haematology finds itself in this country. The haematologist must also be a physician, and the training he should undergo must be such that he does not lose his clinical skills on the way but rather continues to use and develop them. To this end the relevant examining body should insist on a substantial amount of clinical work in general medicine throughout the period of training leading to membership of the College of Pathologists. Indeed the regulations requiring an examination in two disciplines of pathology in the primary examination could well be reconsidered. On the other hand a physician wishing to practise haematology, at whatever level, must be trained as a haematologist, and one year in a haematology laboratory in the early phase of training, a recommended minimum, can hardly be considered as adequate in this sense.

Thus, whether a doctor enters haematology through clinical medicine or through the laboratory, he should in the end be able to take care of patients with blood diseases and to take charge of the running of a haematology laboratory. Either kind of doctor should have access to beds, and both should be members of a single department. Some such scheme might meet the aspirations of physicians wishing to enter haematology and would not prevent those who enter the specialty via the laboratory from practising medicine in the fullest sense. Moreover, it would allow the provision of the kind of care desired by the Royal College of Physicians.

\footnotetext{
1 See summary at page 839.

2 Howie, J., Lancet, 1969, 1, 621.
} 